\title{
Growing Up and Moving On - Transition of Care for Patients with Childhood-onset Rheumatic Disease
}

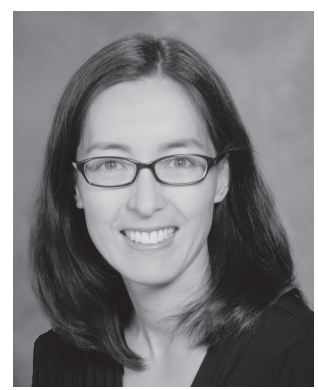

Transition, as defined by the Society of Adolescent Health and Medicine, is the "purposeful, planned movement of adolescents and young adults with chronic physical and medical conditions from child-centered to adult-oriented healthcare systems" 1 . Included in this group is the growing population of adolescents and young adults with childhood-onset rheumatic conditions, such as juvenile idiopathic arthritis (JIA) and systemic lupus erythematosus (SLE), as well as several other less common chronic inflammatory conditions. Recent longterm outcome studies have demonstrated that the majority of children with JIA continue to have active disease into adulthood, dispelling the notion that children can "outgrow" JIA ${ }^{2,3}$. Similarly, newer literature suggests that patients with childhood-onset SLE are likely to require treatment into adulthood, and are at significant risk for early morbidity and mortality in young adulthood ${ }^{4,5,6}$. These findings highlight the importance of ensuring that our patients transition successfully from pediatric to adult care, and that this transition is seamless without disruptions in treatment or planned followup. Fractured transition has the potential to lead to poor healthcare outcomes and increased healthcare system $\operatorname{costs}^{7,8,9}$.

Studies examining transition in pediatric rheumatology and other chronic childhood diseases suggest that significant barriers exist with the current healthcare transition process. Using data from the National Survey of Children with Special Health Care Needs, Scal, et al reported on the proportion of adolescents with arthritis who received transition counseling. They determined that only half of young people had had a discussion with their provider about how their health needs will change into adulthood. Other transition issues that were addressed less frequently included acquiring insurance (22.5\%) and transfer of care to an adult provider $(19 \%)^{10}$. In a Canadian study describing the prevalence of successful transfer of care among patients with congenital heart disease, only $47 \%$ of subjects successfully transferred care, which was defined as attendance at an adult cardiology visit after discharge from pediatric cardiology care ${ }^{11}$. Potential barriers to successful transfer of care include factors attributable to the patient (lack of adherence to treatment and followup recommendations), the physician (lack of familiarity with or time to coordinate the transition process, inadequate communication between old and new providers), and the healthcare system (lack of insurance, limited access to care) ${ }^{12,13,14,15}$.

Recognizing the potential for a coordinated transition program to ensure seamless care along the healthcare continuum, several healthcare institutions, specialties, and disease specific subgroups have developed and implemented formalized transition programs. Many of these programs incorporate the "Six Core Elements of Health Care Transition" described by the Center for Health Care Transition Improvement as part of the "Got Transition" program. These elements provide the framework for the essential steps of the healthcare transition process in both pediatric and adult healthcare settings. The elements include (1) Development of transition and young adult privacy and consent policies; (2) Creation of transitioning and young adult patient registries to monitor progress and outcomes; (3) Transition preparation including identification of gaps in transition readiness; (4) Transition planning including identification of adult providers and the development of a Health Care Transition Action Plan; (5) Transition and Transfer of Care including communication between pediatric and adult providers; and (6) Transition completion.

Despite the recent development of both formalized and informal transition programs there remains a lack of clarity regarding the best metrics for measuring transition program "success." Potential outcome measures include assessment of individual patient measures (e.g., achievement of transition readiness, improved medication adherence or disease control, and patient or family satisfaction) or healthcare system measures (e.g., successfully establishing care with an adult provider and reduction in costs of care).

See Transitioning youth with rheumatic conditions, April 2014;41:768-79

Personal non-commercial use only. The Journal of Rheumatology Copyright (c) 2014. All rights reserved. 
A handful of studies have demonstrated a positive effect of disease-specific transition programs on patient or healthcare system outcomes ${ }^{16,17,18}$.

It is in this context, then, that in the April 2014 issue of The Journal, Chira and colleagues provide a current description of transitional care among 158 North American pediatric rheumatologists representing 74 practice sites ${ }^{19}$. Potential subjects were recruited from the membership of the Childhood Arthritis and Rheumatology Research Alliance (CARRA). Participants completed an e-mailed survey designed to assess (1) current transition practices, (2) provider knowledge about transition policies, (3) barriers and opportunities for implementation of transitional care, and (4) prospects to improve transition through evaluation. When possible, the responses of the pediatric rheumatology cohort were compared to responses obtained from the American Academy of Pediatrics (AAP) 2008 survey on transitional care. The authors found that one-third of respondents reported access to a structured transition program; these programs were more common in Canadian (vs US) institutions. Half the respondents reported having either a formal written transition policy or using an informal approach to transition. Eighty-three percent of subjects surveyed desired rheumatology-specific guidelines for transition. Several barriers to developing adequate transition factors were identified including inadequate training, time, resources, or reimbursement for time spent. As compared to the AAP survey respondents, the CARRA respondents were more likely to assist with referral to adult specialists, to assist with identifying insurance options, and to provide educational packets or handouts, but less likely to assist in creating a portable medical summary. Both groups had a low percentage of respondents who assisted in creating an individualized healthcare transition plan.

These findings highlight the interest in and need for a rheumatology specific transition program that addresses the needs of pediatric and adult providers, patients, and their families. It is encouraging that the majority of respondents had developed either a formalized or informal transition program. Despite the existence of these programs, most respondents still desired rheumatology-specific guidelines for transition. To inform the development of these guidelines, it would be useful to learn more about the existing programs, including the tools and resources used and any outcome measures being collected.

This study also identified commonly cited barriers to formalized transition programs including the time, personnel, and financial resources needed to implement this type of program. Limited resources may present a significant barrier in pediatric rheumatology programs where there are a limited number of clinical providers and staff providing care for a large panel of transition-aged patients. In these types of settings, an institutional or even healthcare-system-wide transition program can be particularly beneficial and cost-effective, using resources across multiple clinics and subspecialties instead of focusing on one specific clinic or disease. Implementation of a transition program across an insurance or healthcare system is also more likely to lead to the engagement of adult primary and subspecialty care, which many have identified as an essential component to the success of a transition program.

To justify the investment of valuable resources into developing and sustaining a transition program, it is imperative that these programs be rigorously evaluated. The evaluation should consider the effect of the program on the patient/family/provider experience and satisfaction, short and longterm clinical outcomes, and healthcare use and costs. Perhaps one of the biggest challenges to assessing the success of these programs is obtaining outcomes data once a patient has transitioned to an adult provider who may be at another institution or in another healthcare system. As the authors of this study suggest in their discussion, patient-reported outcomes may play a critical role in evaluating the longterm success of these types of programs.

Clinical experience and prior research has shown that transition can be a fragile period medically, socially, and developmentally for young people with chronic illness. This study demonstrates the pediatric rheumatology community's commitment to improving transitional care, and identifies important gaps in knowledge and resources for implementing formalized transition programs. As the study's authors highlighted in their discussion, more research is needed to understand how to optimize transitional care for the expanding population of adolescents and young adults with childhood-onset rheumatic disease.

\author{
AIMEE HERSH, MD, \\ Department of Pediatrics, \\ University of Utah's Primary Children's Medical Center, \\ Salt Lake City, Utah, USA
}

Address correspondence to Dr. Hersh, Department of Pediatrics, University of Utah's Primary Children's Medical Center, 295 Chipeta Way, Salt Lake City, Utah 84103, USA.

E-mail: aimee.hersh@hsc.utah.edu

\section{REFERENCES}

1. Blum RW, Garell D, Hodgman CH, Jorissen TW, Okinow NA, Orr DP, et al. Transition from child-centered to adult health-care systems for adolescents with chronic conditions. A position paper of the Society for Adolescent Medicine. J Adolesc Health 1993;14:570-6.

2. Minden K, Niewerth M, Listing J, Biedermann T, Bollow M, Schöntube M, et al, Long-term outcome in patients with juvenile idiopathic arthritis. Arthritis Rheum 2002;46:2392-401.

3. Oen K, Malleson PN, Cabral DA, Rosenberg AM, Petty RE, Cheang M. Disease course and outcome of juvenile rheumatoid arthritis in a multicenter cohort. J Rheumatol 2002;29:1989-99.

4. Hersh AO, Trupin L, Yazdany J, Panopalis P, Julian L, Katz P, et al. Childhood-onset disease as a predictor of mortality in an adult cohort of patients with systemic lupus erythematosus. Arthritis Care Res 2010;62:1152-9. 
5. Hersh AO, von Scheven E, Yazdany J, Panopalis P, Trupin L, Julian $\mathrm{L}$, et al. Differences in long-term disease activity and treatment of adult patients with childhood- and adult-onset systemic lupus erythematosus. Arthritis Rheum 2009;61:13-20.

6. Tucker LB, Uribe AG, Fernández M, Vilá LM, McGwin G, Apte $\mathrm{M}$, et al. Adolescent onset of lupus results in more aggressive disease and worse outcomes: results of a nested matched case-control study within LUMINA, a multiethnic US cohort (LUMINA LVII). Lupus 2008;17:314-22.

7. McDonnell WM, Kocolas I, Roosevelt GE, Yetman AT. Pediatric emergency department use by adults with chronic pediatric disorders. Arch Pediatr Adolesc Med 2010;164:572-6.

8. Pinsky BW, Takemoto SK, Lentine KL, Burroughs TE, Schnitzler MA, Salvalaggio PR. Transplant outcomes and economic costs associated with patient noncompliance to immunosuppression. Am J Transplant 2009;9:2597-606.

9. Shrestha SS, Zhang P, Barker L, Imperatore G. Medical expenditures associated with diabetes acute complications in privately insured U.S. youth. Diabetes Care 2010;33:2617-22 .

10. Scal P, Horvath K, Garwick A. Preparing for adulthood: health care transition counseling for youth with arthritis. Arthritis Rheum 2009;61:52-7.

11. Reid GJ, Irvine MJ, McCrindle BW, Sananes R, Ritvo PG, Siu SC, et al. Prevalence and correlates of successful transfer from pediatric to adult health care among a cohort of young adults with complex congenital heart defects. Pediatrics 2004;113 Pt 1:e197-205.

12. Callahan ST, Winitzer RF, Keenan P. Transition from pediatric to adult-oriented health care: a challenge for patients with chronic disease. Curr Opin Pediatr 2001;13:310-6.
13. Geenen SJ, Powers LE, Sells W. Understanding the role of health care providers during the transition of adolescents with disabilities and special health care needs. J Adolesc Health 2003;32:225-33.

14. Reiss JG, Gibson RW, Walker LR. Health care transition: youth, family, and provider perspectives. Pediatrics 2005;115:112-20.

15. Robertson LP, McDonagh JE, Southwood TR, Shaw KL; British Society of Paediatric and Adolescent Rheumatology. Growing up and moving on. A multicentre UK audit of the transfer of adolescents with juvenile idiopathic arthritis from paediatric to adult centred care. Ann Rheum Dis 2006;65:74-80.

16. Holmes-Walker DJ, Llewellyn AC, Farrell K. A transition care programme which improves diabetes control and reduces hospital admission rates in young adults with Type 1 diabetes aged 15-25 years. Diabet Med 2007;24:764-9.

17. Okumura MJ, Ong T, Dawson D, Nielson D, Lewis N, Richards M, et al. Improving transition from paediatric to adult cystic fibrosis care: programme implementation and evaluation. BMJ Qual Saf 2014; Jan 10 (E-pub ahead of print).

18. Shaw KL, Watanabe A, Rankin E, McDonagh JE. Walking the talk. Implementation of transitional care guidance in a UK paediatric and a neighbouring adult facility. Child Care Health Dev 2013; Oct 21 (E-pub ahead of print)

19. Chira P, Ronis T, Ardoin S, White P. Transitioning youth with rheumatic conditions: Perspectives of pediatric rheumatology providers in the United States and Canada. J Rheumatol 2014;41:768-79.

J Rheumatol 2014;41:829-31; doi:10.3899/jrheum.140140 